\title{
Indirect Speech Acts and Their Use in Three Channels of Communication
}

\author{
Lewis Hassell, \\ SmithKline Beecham \\ Margaret Christensen, \\ M. Christensen Associates, Inc., Multimedia
}

\begin{abstract}
This paper presents the results from a study analyzing the distribution of speech acts across three communication channels: email, face-to-face and telephone. The study involved an actual group involved working together on a project. The patterns of speech acts across the three channels are presented. In particular, the use of the indirect form of each speech act is highlighted. It is shown that the indirect form plays a major role across speech acts and channels, with a few noteworthy exceptions.
\end{abstract}

\section{$1 \quad$ Statement of Problem}

\subsection{Introduction}

Speech act theory (particularly as developed by John Searle $[7,8,9]$ has been fertile ground for work in CSCW. Besides academic research (SAMPO, etc.), speech act theory recently has been used to build a commercial system (a workflow product marketed by Action Technologies). Much, if not most of this work has viewed modeling strictly from the point of view of direct speech acts. Searle, however, recognizes the indirect form of each speech act as being an important form of that act (see, e.g., "Indirect Speech Acts" in [8]). It would be useful to examine the use of the indirect form in collaborative (project-oriented) work to see what patterns occur in various media. In this way some light could be shed on the degree to which the support of indirect speech acts would be important in collaborative systems.

Recently, a small study was undertaken in an attempt to understand the applicability of speech act theory to analyzing communication patterns in three different media: face-to-face, telephone and email. ${ }^{1}$

\subsubsection{Searle's Analysis}

Speech act theory was first developed by J. L. Austin in a series of lectures at Oxford University [1]. Austin was advancing a philosophy of language that directly critiqued the prevailing notion (the "age-old assumption of philosophy") that "to say something ... is always simply to state something" (p.12). Austin contended that besides the constative class of verbs (i.e., verbs that stated something about something) there was also a class of verbs he called performatives. Performatives did not report about doing something, their utterance actually constituted performing an action. Because performatives are actions, they cannot be considered to be either true or false but only "felicitous" or "infelicitous". Austin defined an illocution, or an illocutionary act, as an act performed in uttering a sentence with a performative verb.

\footnotetext{
${ }^{1}$ The study wished to compare the use of email with other, more "conventional" forms of communication in a real world setting. The channels used by this group, besides email, happened to be face-to-face and the telephone. No use of hand written messages or fax was made during the period the group was studied.
}

Communication Modeling - The Language/Action Perspective, 1996 
John Searle, a student of Austin's, expanded on and codified his teacher's work [7]. Searle logically enumerated the five possible categories of speech acts and strictly delimited necessary and sufficient conditions for them. Searle pointed out that Austin's taxonomy was of English verbs, rather than of linguistic acts. Austin viewed his taxonomy as "not the least definitive" ([1], p.151), whereas Searle claimed his is exhaustive. His taxonomy broke speech acts down as follows ([8], pp. 12-30):

1) assertives, which commit the speaker to the truth or falsity of something's being the case.

2) directives, which constitute an attempt by the speaker to get the listener to do something.

3) commissives, which commit the speaker to do something.

4) expressives, which express the psychological state of the speaker.

5) declarations, which brings about a correspondence between the propositional content of the statement and reality.

Searle also developed the notion of indirect speech acts.

"In indirect speech acts the speaker communicates to the hearer more than he actually says by way of relying on their mutually shared background information, both linguistic and nonlinguistic, together with the general powers of rationality and inference on the part of the hearer. To be more specific, the apparatus necessary to explain the indirect part of indirect speech acts includes a theory of speech acts [and] certain general principles of cooperative conversation ..." ([8], pp. 31-32).

As we shall see, the notion of indirect speech acts is not without controversy. It does point out, however, that in the normal course of human communication, the complete intent of any piece of discouse cannot be determined by lexical or semantic analysis, but must be determined by context.

\subsubsection{Reactions to Speech Act Theory}

While speech act theory has provided fertile ground for various approaches to everything from linguistics to cognitive science to information systems, it too is not without its critics. The criticisms seem not to focus on the fact that Searle left certain important aspects out of his analysis or that he was fundamentally wrong but that he did not emphasize particular aspects of language enough, or that his taxonomy and/or approach in general is derivative and not fundamental.

In the area of CSCW, Bowers and Churcher [2] argue "that communicative actions should be seen as essentially embedded in dialogical contexts" (p.197). They criticize speech act theory for ignoring social and historical context. However, even the calculus envisioned by Searle and Vandervenken [9] includes the element of context as fundamental. In fact, they state, "The single most important question [a theory of illocutionary logic] must answer is simply this: Given that a speaker in a certain context [emphasis mine] of utterance performs a successful illocutionary act of a certain form, what other illocutions does the performance of that act commit him to?"(p. 6).

Levinson's classic 1983 work [6], Pragmatics, contains a lengthy discussion of speech act theory. Levinson's main criticism of Searle is especially relevant for this discussion. He rejects what he calls the "literal force hypothesis" (LFH) to which Searle is committed. Searle assumes that indirect speech acts can be reduced to their direct form and that the (literal) force of that direct form is built into the sentence. Levinson points out that "most usages [of sentences] are indirect" (p. 264). With Gazdar [4], Levinson denies that sentences have illocutionary force. Illocutionary force only comes from sentences in context. What Levinson does seem to admit, however, is that there are sentences which express their force more directly and those which require more context in order for proper identification of their force.

\section{Method}

This study used Searle's taxonomy of speech acts, including his analysis of indirect speech acts [7,8].

The study lasted for a period of six weeks. There were three large face-to-face meetings, and four smaller meetings. There were 31 internet-based email messages. There were only two telephone conversations. 
The participants were thoroughly acquainted with email. Feenberg [3] noted that laws of communication are conventions. It is probable, therefore, that any group that is familiar with email will use it differently than one that is unfamiliar with it.

The data were collected toward the end of the project. It may be that different communication patterns occur at different periods of a project. Hjelmquist [5] suggested (pp. 957-958) that as a group matures, its use of media, particularly CSCW-based systems, settles into a mature pattern which is different than what it would have been at the beginning.

\subsection{Subjects}

The subjects of this study were members of a research project in the field of computer science. There were nine people in the group as studied: four faculty and five (graduate) student assistants.

English is a second language for two of the faculty and two of the students. All, however, were fluent in English. Both of the foreign faculty members were Europeans and had been teaching at English speaking universities for over 10 years. The two students were non-European. Outside of making brief reports at monthly meetings, their communications were generally limited to small face-to-face meetings. This is not viewed as being detrimental to this study, since transnational project teams are an established reality in today's world.

\subsection{Materials}

The internet was used for all electronic mail communication. Hand-held tape recorders were used to record both face to face and phone conversations. Tape recorders were supplied to all faculty members and one was left in the room at the institution where much of the programming took place.

\subsection{Design and Procedures}

All study participants had the author's email address. It was provided both via email and on paper. This was a formality, since they already had this information from the pilot study but it was repeated for completeness. The author received email either by being included in the "To:" or "CC:" fields of the message or by having the message "Forward"-ed to him.

Both face-to-face and telephone conversations were recorded on hand-held tape recorders. Participants using the recorders were asked to give their name, the names of other participant(s), the date and time of the conversation.

Taped conversations were transcribed and, along with the written correspondence (email), all speech acts were "coded". There were several issues to be resolved in the coding of speech acts. The first concerned the repetition of an utterance. Speech act theory distinguishes between an utterance act and a speech act. If ' $\mathrm{X}$ ' is a particular speech act, then every time the speaker says ' $\mathrm{X}$ ', there is a new utterance of ' $\mathrm{X}$ ', but the same speech act. Thus, if someone repeated the same request, commitment, assertion, etc., there may have been many utterance acts, but there was only one speech act.

The second issue was in the coding of indirect speech acts. For instance, one of the co-investigators could say, "We need a module to do Y." This could be coded as an assertive that is simply expressing of the need in the project for a module to perform that particular function. Alternatively, it could have been a directive to the listener to write the particular piece of code to perform that function. This may seem an awkward theoretical problem, but it is less problematic in reality because speech act theory permits recognition of the context in which a speech act occurs. If, for example, the statement above was issued in a monthly meeting to all members of the project, it would probably be construed as an assertive. If, however, it were said to one of the students in a oneon-one face-to-face conversation, it would probably be a directive. The final statement on what type of speech act this actually was would depend upon knowing how the listener(s) perceived it (i.e., the "uptake" of the listener.

Two independent volunteers who were not linguists did the coding based on an algorithm and instructions given to the them. To permit the degree of inconsistency, if any, in coding between coders to be determined, all text was coded by both people. To ensure that the instructions were adequate, the coding was checked to ensure that at least $75 \%$ of the coding was the same. The coders were $79.5 \%$ in agreement. The comparison was done using the chi-square test. 


\section{Findings}

\subsection{Overview}

In the first pass of coding, the statements were coded for their straightforward speech act structure. In the second pass of the coding, the statements were coded for the intention of the speakers or writers. There were a number of interesting results that must be accounted for, particularly when considering the use of CSCW-based systems as part of a communication system. And given the fact that there was a sufficient correlation (79.5\%) between the two coders, one may have some confidence in the conclusions.

Not surprisingly, by far the most prevalent type of speech act was the assertive (Figure 1). It was more numerous than all other types of speech acts combined. Even when speech acts were counted in the second pass, assertives were still the most numerous (Figure 2). This held true across all channels. On the second pass, however, between 17-30\% of the assertives, depending on channel, had been recoded as the indirect form of other speech acts (Table 5). And if the results of Pass 1 and Pass 2 are compared (Tables 1 and 2) it can be seen that the difference between Pass 1 and Pass 2 is non-random ( $p<0.001$ in both cases). They indicate that a great many non-assertives are made in the indirect form.

Non-assertives are twice as likely to be made indirectly as to be made directly. There is one interesting exception to this general rule. In the email channel, the direct expressives were equal in number to indirect expressives (Table 15). Expressives and email will be discussed more later. For the time being, it is sufficient to note that this statistic seems to say something about the way this medium is used, and perhaps why email messages sometimes seem so inflammatory.

Of the approximately 6300 speech acts in this study, nearly 5900 were coded as assertives in Pass 1 . By Pass 2, less than 4900 were considered to intend an assertion. Almost no other speech acts were recoded as another type of speech act, and the two that were may have been due to coder error. This is indicated by Searle's analysis [8]. It would seem that assertives are the raw material from which the other, indirect types, of speech acts are made.

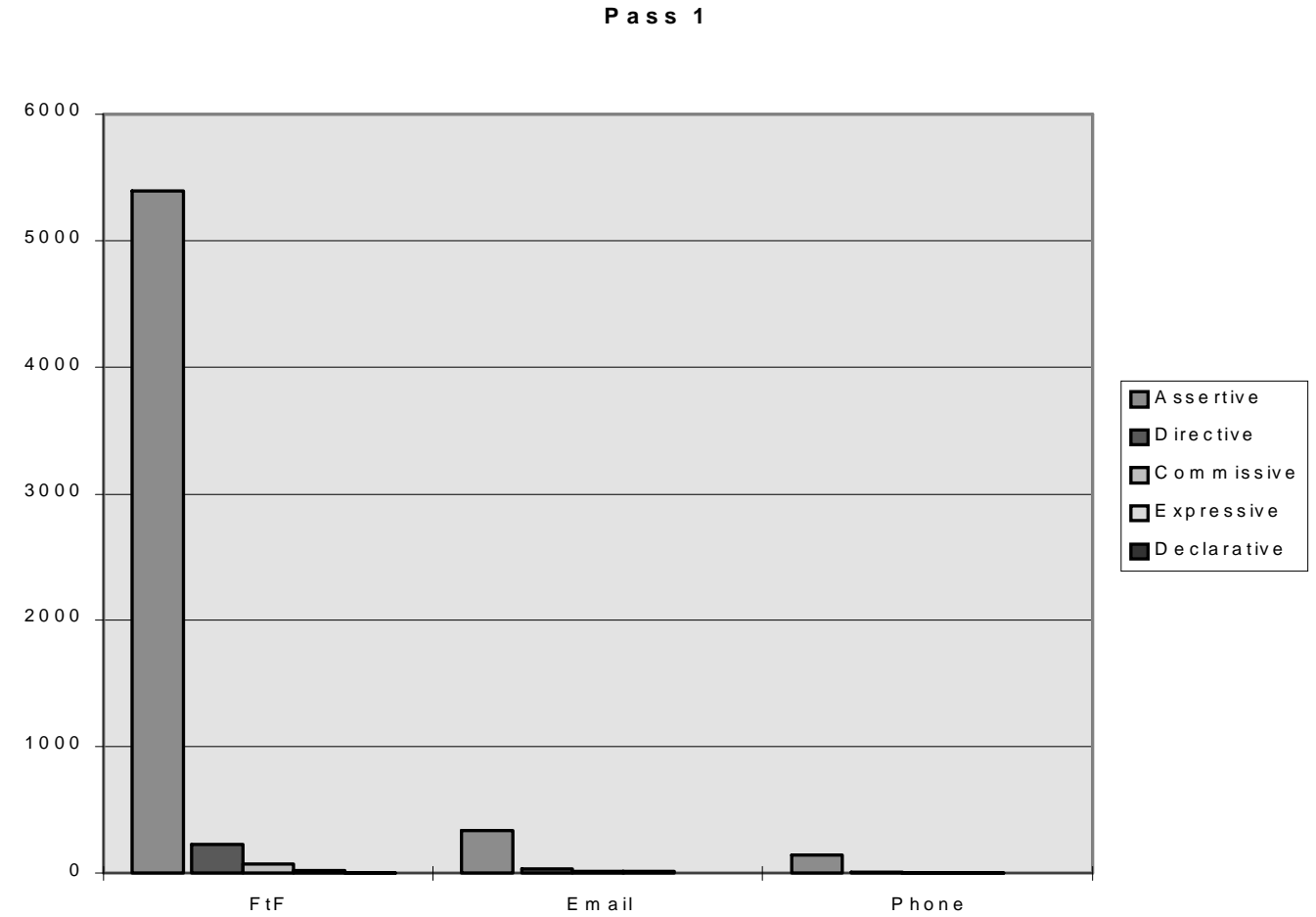

Figure 1 - Distribution of speech acts across channels by counts, Pass 1 


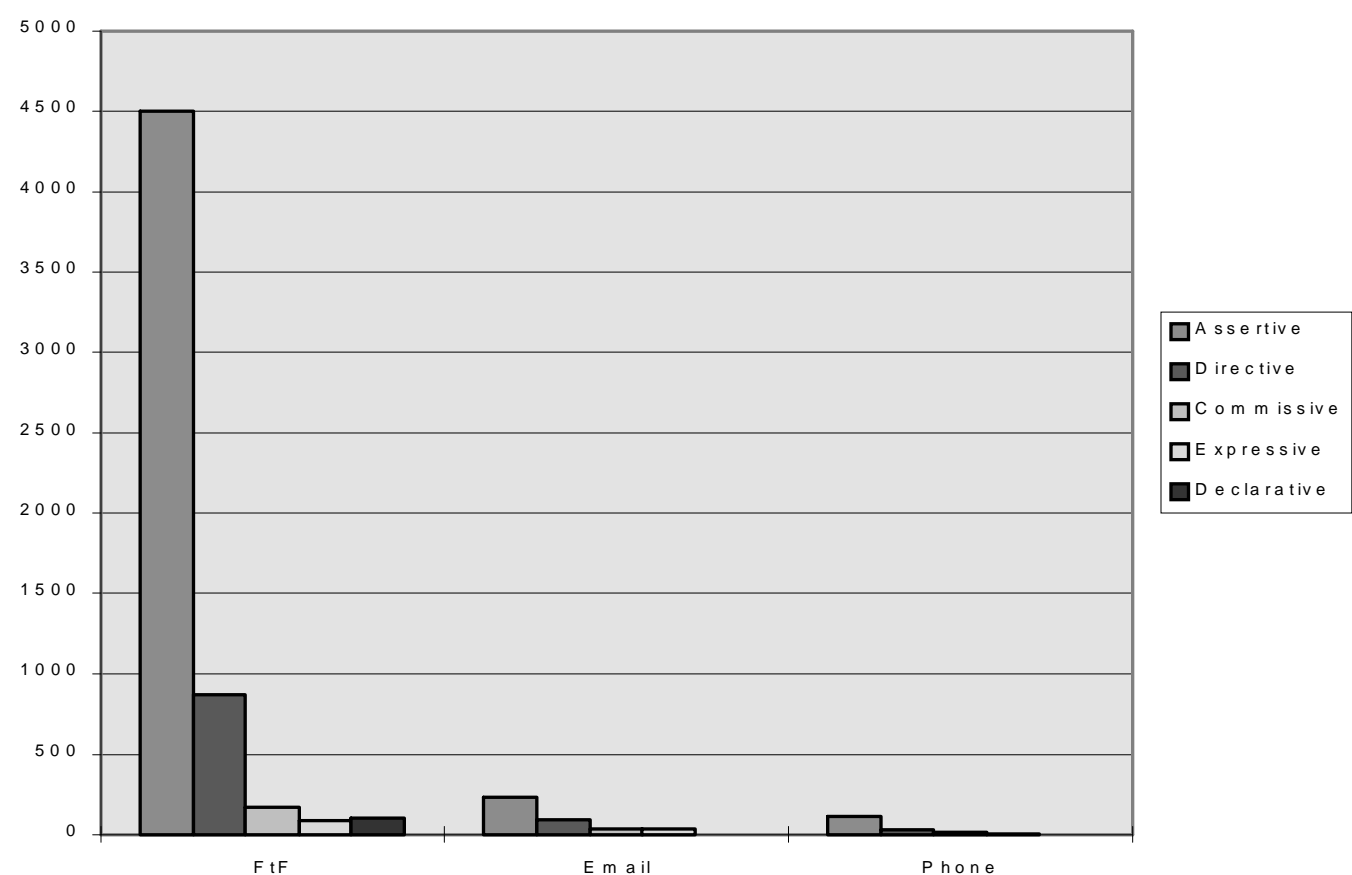

Figure 2 - Distribution of speech acts across channels by counts, Pass 2

\begin{tabular}{|l|r|r|r|r|r|r|}
\hline & Assertive & Directive & Commissive & Expressive & Declarative & Total \\
\hline Pass 1 & 5872 & 281 & 99 & 45 & 4 & $\mathbf{6 3 0 1}$ \\
\hline Pass 2 & 4851 & 996 & 220 & 132 & 102 & $\mathbf{6 3 0 1}$ \\
\hline Total & $\mathbf{1 0 7 2 3}$ & $\mathbf{1 2 7 7}$ & $\mathbf{3 1 9}$ & $\mathbf{1 7 7}$ & $\mathbf{1 0 6}$ & $\mathbf{1 2 6 0 2}$ \\
\hline Chi Sq & $\mathbf{6 7 6 . 8 1 1 2 7}$ & $\mathbf{d f}=\mathbf{4}$ & $\mathbf{p}<\mathbf{0 . 0 0 1}$ & & & \\
\hline
\end{tabular}

Table 1 - Distribution of speech acts, Pass 1 and Pass 2

\begin{tabular}{|c|r|r|r|r|r|}
\hline & Assertive & Directive & Commisive & Expressive & Declarative \\
\hline Pass1 & 5394 & 234 & 78 & 22 & 4 \\
\hline Pass2 & 4502 & 872 & 171 & 88 & 99 \\
\hline Total & $\mathbf{9 8 9 6}$ & $\mathbf{1 1 0 6}$ & $\mathbf{2 4 9}$ & $\mathbf{1 1 0}$ & $\mathbf{1 0 3}$ \\
\hline Chi Sq & $\mathbf{6 8 6 . 9 0 7 1 3}$ & $\mathbf{d f = 1 4}$ & $\mathbf{n}<\mathbf{0 . 0 0 1}$ & & \\
\hline
\end{tabular}

Table $2 a$-Distribution of speech acts for Face To Face, Pass 1 and Pass 2

\begin{tabular}{|c|r|r|r|r|r|}
\hline & Assertive & Directive & Commisive & Expressive & Declarative \\
\hline Pass1 & 333 & 36 & 16 & 20 & 0 \\
\hline Pass2 & 234 & 92 & 37 & 40 & 2 \\
\hline Total & $\mathbf{5 6 7}$ & $\mathbf{1 2 8}$ & $\mathbf{5 3}$ & $\mathbf{6 0}$ & $\mathbf{2}$ \\
\hline Chi Sq & $\mathbf{6 8 6 . 9 0 7 1 3}$ & $\mathbf{d f = 1 4}$ & $\mathbf{n}<\mathbf{0 . 0 0 1}$ & & \\
\hline
\end{tabular}

Table $2 b$-Distribution of speech acts for Email, Pass 1 and Pass 2 


\begin{tabular}{|c|r|r|r|r|r|}
\hline & Assertive & Directive & Commisive & Expressive & Declarative \\
\hline Pass1 & 145 & 11 & 5 & 3 & 0 \\
\hline Pass2 & 115 & 32 & 12 & 4 & 1 \\
\hline Total & $\mathbf{2 6 0}$ & $\mathbf{4 3}$ & $\mathbf{1 7}$ & $\mathbf{7}$ & $\mathbf{1}$ \\
\hline Chi Sq & $\mathbf{6 8 6 . 9 0 7 1 3}$ & $\mathbf{d f = 1 4}$ & $\mathbf{n}<\mathbf{0 . 0 0 1}$ & & \\
\hline
\end{tabular}

Table $2 c$-Distribution of speech acts for Phone, Pass 1 and Pass 2

\begin{tabular}{|l|l|l|l|l|l|l|}
\hline & Assertive & Directive & Commissive & Expressive & Declarative & Total \\
\hline FtF & $5394(94 \%)$ & $234(4 \%)$ & $78(1.5 \%)$ & $22(0.4 \%)$ & $4(0.1 \%)$ & $\mathbf{5 7 3 2 ( 1 0 0 \% )}$ \\
\hline Email & $333(82 \%)$ & $36(9 \%)$ & $16(4 \%)$ & $20(5 \%)$ & $0(0 \%)$ & $\mathbf{4 0 5 ( 1 0 0 \% )}$ \\
\hline Phone & $145(88.4 \%)$ & $11(6.7 \%)$ & $5(3 \%)$ & $3(1.9 \%)$ & $0(0 \%)$ & $\mathbf{1 6 4 ( 1 0 0 \% )}$ \\
\hline Total & $\mathbf{5 8 7 2}$ & $\mathbf{2 8 1}$ & $\mathbf{9 9}$ & $\mathbf{4 5}$ & $\mathbf{4}$ & $\mathbf{6 3 0 1}$ \\
\hline ChiSq= & $\mathbf{1 5 9 . 3 3 1 9 8 9}$ & $\mathbf{d f}=\mathbf{8}$ & $\mathbf{p}<. \mathbf{0 0 1}$ & & & \\
\hline
\end{tabular}

Table 3 - Distribution of speech acts across channels, Pass 1

\begin{tabular}{|l|l|l|l|l|l|l|}
\hline & Assertive & Directive & Commissive & Expressive & Declarative & Total \\
\hline FtF & $4502(78.5 \%)$ & $872(15.2 \%)$ & $171(3 \%)$ & $88(1.5 \%)$ & $99(1.8 \%)$ & $\mathbf{5 7 3 2 ( 1 0 0 \% )}$ \\
\hline Email & $234(58 \%)$ & $92(22.7 \%)$ & $37(9 \%)$ & $40(10 \%)$ & $2(0.3 \%)$ & $\mathbf{4 0 5 ( 1 0 0 \% )}$ \\
\hline Phone & $115(70 \%)$ & $32(20 \%)$ & $12(7.3 \%)$ & $4(2.4 \%)$ & $1(0.3 \%)$ & $\mathbf{1 6 4 ( 1 0 0 \% )}$ \\
\hline Total & $\mathbf{4 8 5 1}$ & $\mathbf{9 9 6}$ & $\mathbf{2 2 0}$ & $\mathbf{1 3 2}$ & $\mathbf{1 0 2}$ & $\mathbf{6 3 0 1}$ \\
\hline ChiSq $=$ & $\mathbf{2 1 5 . 5 6 1 3}$ & $\mathbf{d f}=\mathbf{8}$ & $\mathbf{p}<\mathbf{0 . 0 0 1}$ & & & \\
\hline
\end{tabular}

Table 4 - Distribution of speech acts across channels, Pass 2

\begin{tabular}{|l|r|r|r|r|r|}
\hline & $\begin{array}{c}\text { Initially } \\
\text { Direct }\end{array}$ & $\begin{array}{c}\text { Used for } \\
\text { Other Acts }\end{array}$ & $\begin{array}{c}\% \text { Used for } \\
\text { Other Acts }\end{array}$ & $\begin{array}{c}\text { Simple } \\
\text { Assertives }\end{array}$ & $\begin{array}{r}\% \text { Used as } \\
\text { Assertives }\end{array}$ \\
\hline Email & 333 & 99 & $30 \%$ & 234 & $70 \%$ \\
\hline FtF & 5394 & 892 & $17 \%$ & 4502 & $83 \%$ \\
\hline Phone & 145 & 30 & $21 \%$ & 115 & $79 \%$ \\
\hline
\end{tabular}

Table 5 - Distribution of assertives, Pass 2

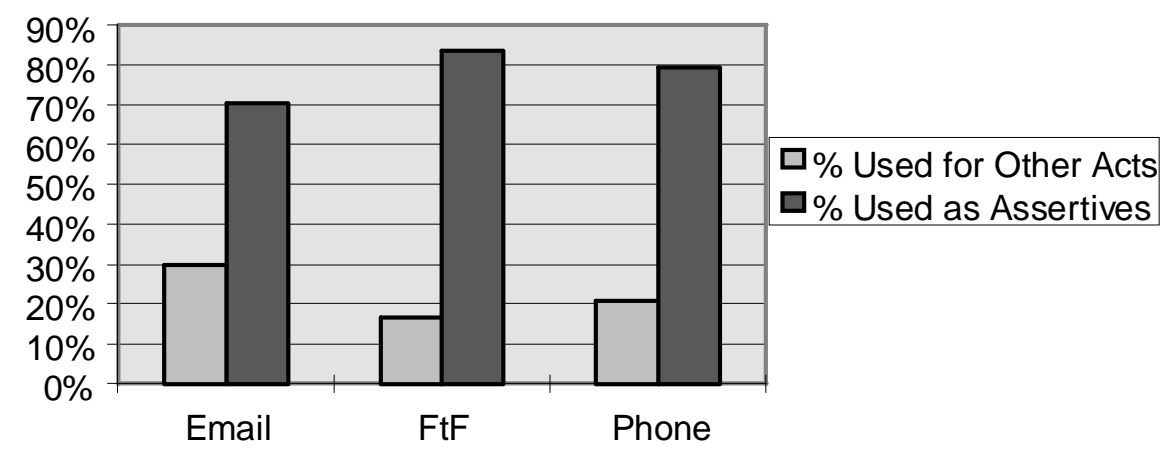

Figure 3 - Distribution of assertives by percentage, Pass 2

\subsection{Indirect Speech Acts by Speech Act Type}

\subsubsection{Directives}

Searle [8] noted that indirect speech acts were constrained by various cultural norms. Since directives are the requesting and ordering speech act type, it is not surprising that one should be circumspect concerning how one issues these requests. Indirect directives received more treatment from Searle than other indirect forms. Table 6 shows that requests are primarily made indirectly. There are a number of points to be remembered here, however. 
First, the group studied was a professional group and it may be that educated people are more polite. Second, the participants were aware that they were being recorded.

As can be seen from Table 6, different channels have different proportions of direct and indirect directives that is statistically significant $(\mathrm{p}=0.04)$.

\begin{tabular}{|l|l|l|l|}
\hline & Direct & Indirect & Total \\
\hline Email & $36(39 \%)$ & $56(61 \%)$ & $\mathbf{9 2 ( 1 0 0 \% )}$ \\
\hline FtF & $234(27 \%)$ & $638(73 \%)$ & $\mathbf{8 7 2 ( 1 0 0 \% )}$ \\
\hline Phone & $11(34 \%)$ & $21(66 \%)$ & $\mathbf{3 2 ( 1 0 0 \% )}$ \\
\hline Total & $\mathbf{2 8 1}$ & $\mathbf{7 1 5}$ & $\mathbf{9 9 6}$ \\
\hline ChiSq= & $\mathbf{6 . 8 3 1 8 6 8 2 8 2}$ & $\mathbf{d f = 2}$ & $\mathbf{p = 0 . 0 4}$ \\
\hline
\end{tabular}

Table 6 - Directives per channel

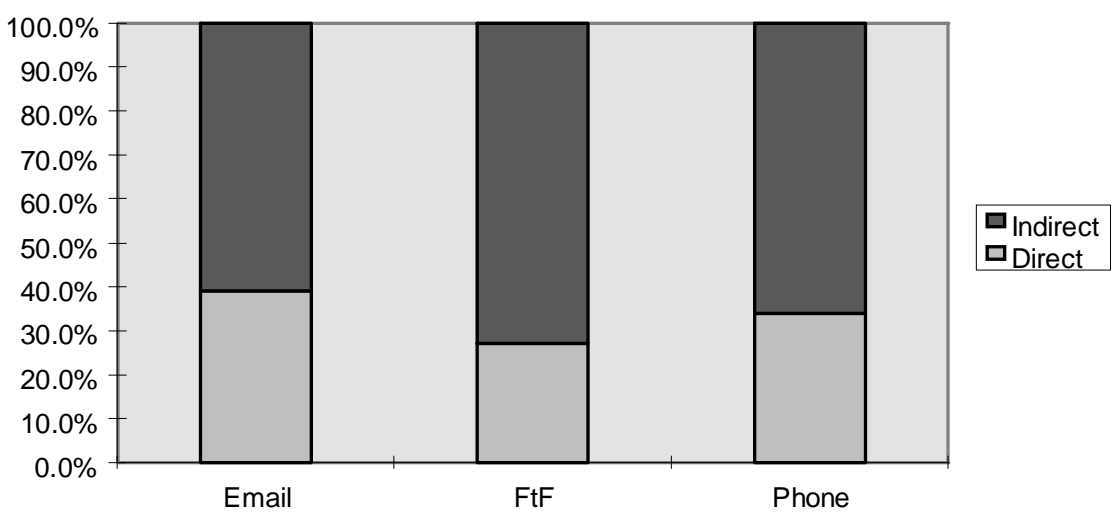

Figure 4 - Directives per channel by percentage

\subsubsection{Commissives}

Commissives do not occur as often as directives. Directives may sometimes be unsuccessful, thus resulting in no commissive. It cannot be discounted that some "commissives" are achieved via body language, since commissives represent 3\% of all statements in face-to-face whereas they represent $7 \%$ and $9 \%$ in telephone and email, respectively (Table 4). Commissives are still more likely to be made in the indirect mode than the direct, though there are few social constraints on making direct promises.

\begin{tabular}{|l|l|l|l|}
\hline & Direct & Indirect & Total \\
\hline Email & $16(43 \%)$ & $21(57 \%)$ & $\mathbf{3 7}(\mathbf{1 0 0} \%)$ \\
\hline FtF & $78(46 \%)$ & $93(54 \%)$ & $\mathbf{1 7 1}(\mathbf{1 0 0} \%)$ \\
\hline Phone & $5(42 \%)$ & $7(58 \%)$ & $\mathbf{1 2}(\mathbf{1 0 0} \%)$ \\
\hline Total & $\mathbf{9 9}$ & $\mathbf{1 2 1}$ & $\mathbf{2 2 0}$ \\
\hline ChiSq= & $\mathbf{0 . 1 2 6 0 5 9 0 7 3}$ & $\mathbf{d f}=\mathbf{2}$ & NSS \\
\hline
\end{tabular}

Table 7 - Commissives per channel

\footnotetext{
${ }^{2}$ NSS $=$ Not statistically significant.
} 


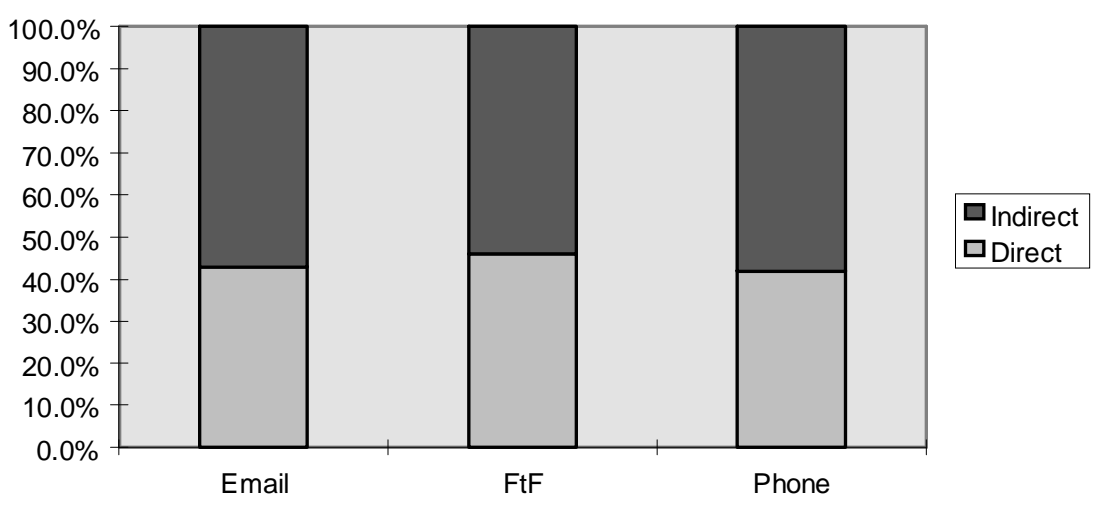

Figure 5 - Commissives per channel by percentage

\subsubsection{Expressives}

The reader will notice that expressives when made face-to-face are three times more likely to be made indirectly as directly. Whereas in email they are as likely to be made directly as indirectly.

\begin{tabular}{|l|l|l|l|}
\hline & Direct & Indirect & Total \\
\hline Email & $20(50 \%)$ & $20(50 \%)$ & $\mathbf{4 0}(\mathbf{1 0 0} \%)$ \\
\hline FtF & $22(25 \%)$ & $66(75 \%)$ & $\mathbf{8 8}(\mathbf{1 0 0} \%)$ \\
\hline Phone & $3(75 \%)$ & $1(25 \%)$ & $\mathbf{4 ( 1 0 0 \% )}$ \\
\hline Total & $\mathbf{4 5}$ & $\mathbf{8 7}$ & $\mathbf{1 3 2}$ \\
\hline ChiSq= & $\mathbf{1 0 . 7 2 1 8 3 9 0 8}$ & $\mathbf{d f}=\mathbf{2}$ & $\mathbf{p}=\mathbf{0 . 0 0 5}$ \\
\hline
\end{tabular}

Table 8 - Expressives per channel

It is also interesting to remember that expressives represent $10 \%$ of the total number of acts in email, yet they make barely $1.5 \%$ in face-to-face (Table 4). There are a number of possible reasons for this distribution in our study. First, the mail messages were all short. None were two pages in length; most were only a half dozen sentences long. All of the recorded face-to-face conversations were much longer. It may be that there is a "minimum requirement" for such acts in discourse and they get diluted over a larger period. Second, there may be an attempt to personalize an impersonal medium.

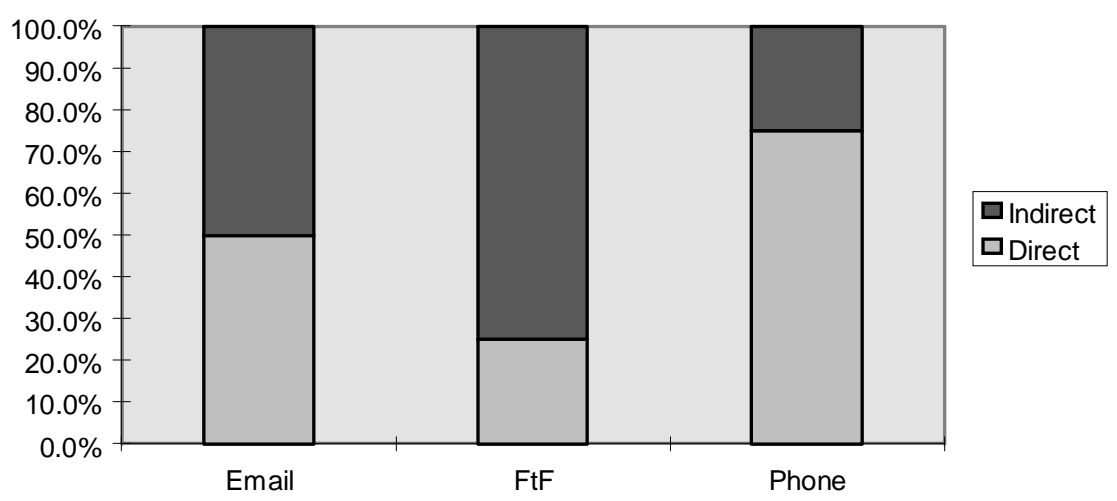

Figure 6 - Expressives per channel by percentage 


\subsubsection{Declaratives}

Declaratives are almost always issued in an indirect manner. Because of the scarcity of data in so many of the cells, a chi-square would be inadvisable. There is an obvious preponderance of declaratives in face-to-face. Since face-to-face communication was either of the small group variety where teachers were overseeing the work of students, or project meetings where the direction of the project was set, this distribution is not surprising. On the other hand, it does seem to indicate that face-to-face is the channel of choice for making important statements, pronouncements, which require the exercise of authority.

\begin{tabular}{|l|r|r|r|}
\hline & Direct & Indirect & Total \\
\hline Email & 0 & 2 & 2 \\
\hline FtF & 4 & 95 & 99 \\
\hline Phone & 0 & 1 & 1 \\
\hline Total & 4 & 98 & 102 \\
\hline
\end{tabular}

Table 9 - Declaratives per channel

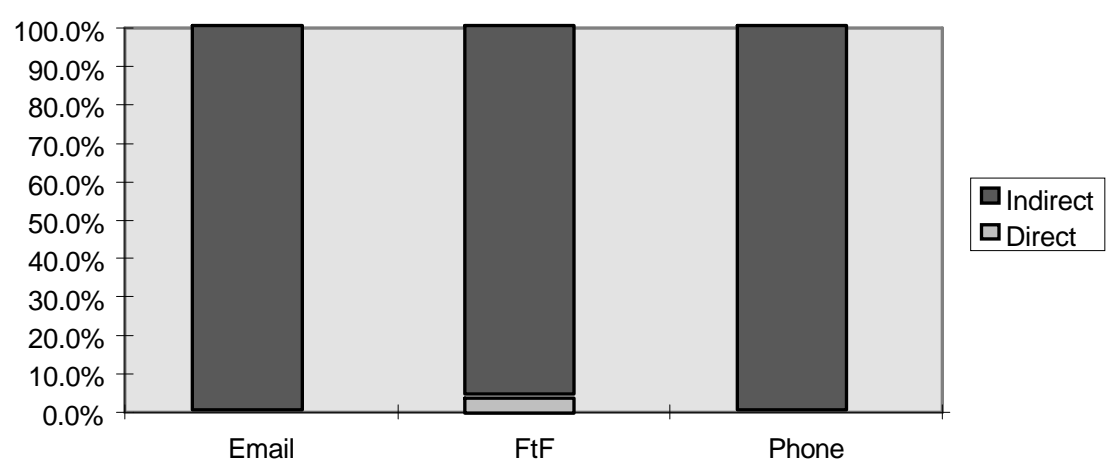

Figure 7 - Declaratives per channel by percentage

\subsection{Indirect Speech Acts by Channel}

\subsubsection{Face-to-face}

Table 10 is for all face-to-face meetings. This includes three major meetings and four smaller meetings made up of subsets of the participants. The chi square shows a high degree of significance for the relative distribution of direct versus indirect forms for speech acts in face-to-face meetings( $\mathrm{p}<0.001)$. One should also note that all nonassertives show a larger percentage in the indirect form. Only commissives approach an even distribution, but even there the indirect form is $54 \%$.

\begin{tabular}{|l|l|l|l|}
\hline & Direct & Indirect & Total \\
\hline Directives & $234(27 \%)$ & $638(73 \%)$ & $\mathbf{8 7 2 ( 1 0 0 \% )}$ \\
\hline Commissives & $79(46 \%)$ & $93(54 \%)$ & $\mathbf{1 7 2 ( 1 0 0 \% )}$ \\
\hline Expressives & $23(26 \%)$ & $66(74 \%)$ & $\mathbf{8 9 ( 1 0 0 \% )}$ \\
\hline Declaratives & $4(4 \%)$ & $95(96 \%)$ & $\mathbf{9 9 ( 1 0 0 \% )}$ \\
\hline Total & $\mathbf{3 4 0}$ & $\mathbf{8 9 2}$ & $\mathbf{1 2 3 2}$ \\
\hline ChiSq= & $\mathbf{5 6 . 8 1 6 9 5 1 1 1}$ & $\mathbf{d f = 3}$ & $\mathbf{p}<\mathbf{0 . 0 0 1}$ \\
\hline
\end{tabular}

Table 10 - Non-assertives in face-to-face 


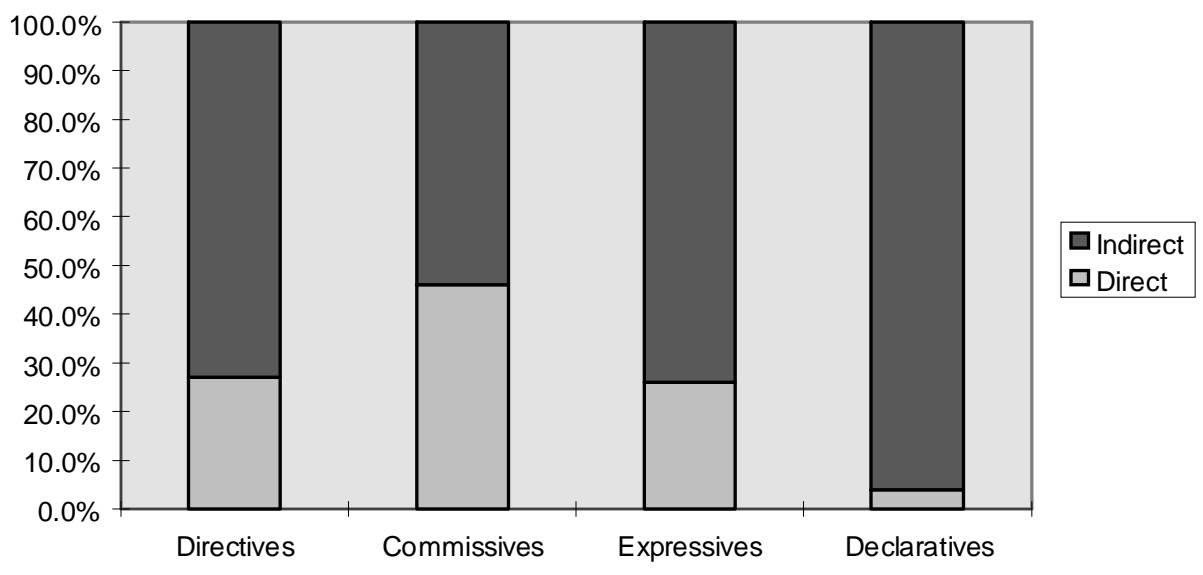

Figure 8 - Non-assertives in face-to-face by percentage

If we compare the distribution of non-assertive speech acts in face-to-face with those of face-to-face and telephone (i.e., voice channels ${ }^{3}$ ), we can see that there are no statistically significant differences. That is to say, the distributions are much the same.

\begin{tabular}{|l|c|r|r|r|r|r|r|r|r|}
\hline & Directive & & Commissive & Expressive & & Declarative & \\
\hline & Direct & Indirect & \multicolumn{1}{|c|}{ Direct } & Indirect & Direct & Indirect & Direct & Indirect & Total \\
\hline Voice & 245 & 658 & 84 & 100 & 26 & 67 & 4 & 96 & $\mathbf{1 2 8 0}$ \\
\hline FtF & 234 & 638 & 79 & 93 & 23 & 66 & 4 & 95 & $\mathbf{1 2 3 2}$ \\
\hline Total & $\mathbf{4 7 9}$ & $\mathbf{1 2 9 6}$ & $\mathbf{1 6 3}$ & $\mathbf{1 9 3}$ & $\mathbf{4 9}$ & $\mathbf{1 3 3}$ & $\mathbf{8}$ & $\mathbf{1 9 1}$ & $\mathbf{2 5 1 2}$ \\
\hline ChiSq= & $\mathbf{0 . 2 4 7 8 3 3}$ & $\mathbf{d f = 7}$ & NSS & & & & & & \\
\hline
\end{tabular}

Table 11 - Non-assertives in face-to-face versus both voice channels

\subsubsection{Large group}

Table 12 below represents a subset of face-to-face data, the three major project meetings. These were formally called, regularly scheduled meetings to discuss overall project goals and to bring members of the project up to date on its progress. All four researchers always attended. Most of the students attended most meetings, though their input was usually in response to faculty inquiries. Among the points of interest is the fact that once again only in commissives do direct and indirect forms approach equal distribution. In this case, however, there are actually slightly more in direct form. This would seem reasonable given the formal nature of the meeting. It is also to be noted that the only direct declaratives occur in large, formal meetings (see Tables 12 and 13). This must be tempered by the fact that it represents only slightly more than one direct declarative per meeting: $5 \%$ of all declaratives.

On the second pass, $80 \%$ of all speech acts were assertives in large face-to-face meetings. The transmission of information was therefore a major part of large group meetings.

\begin{tabular}{|l|l|l|l|}
\hline & Direct & Indirect & Total \\
\hline Directives & $188(28 \%)$ & $472(72 \%)$ & $\mathbf{6 6 0}(\mathbf{1 0 0} \%)$ \\
\hline Commissives & $67(51 \%)$ & $63(49 \%)$ & $\mathbf{1 3 0 ( 1 0 0 \% )}$ \\
\hline Expressives & $14(20 \%)$ & $58(80 \%)$ & $\mathbf{7 2 ( 1 0 0 \% )}$ \\
\hline Declaratives & $4(5 \%)$ & $\mathbf{7 8}(95 \%)$ & $\mathbf{8 2}(\mathbf{1 0 0} \%)$ \\
\hline Total & $\mathbf{2 7 3}$ & $\mathbf{6 7 1}$ & $\mathbf{9 4 4}$ \\
\hline ChiSq= & $\mathbf{5 8 . 6 1 7 1 6 9 6 8}$ & $\mathbf{d f}=\mathbf{3}$ & $\mathbf{p}<\mathbf{0 . 0 0 1}$ \\
\hline
\end{tabular}

Table 12 - Non-assertives in large group

\footnotetext{
${ }^{3}$ It is necessary to lump face-to-face with telephone because there are not enough data in the telephone channel to run a chi square.
} 


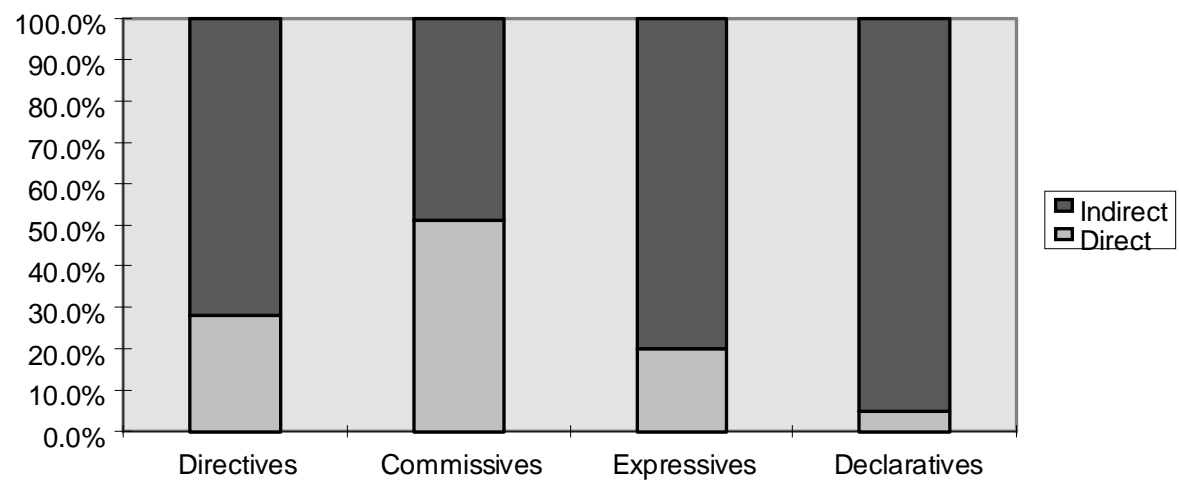

Figure 9 - Non-assertives in large group by percentage

\subsubsection{Small Group}

Small groups were also made up of subsets of the participants. Faculty were sometimes but not always present. Because of the sparseness of data in the direct expressive and the declarative cells, the chi-square test must be considered somewhat suspect. Still, the same overall patterns are seen. It may or may not be significant, but there were no direct declaratives in these smaller, less formal meetings.

On the second pass, assertives were $71 \%$ of all speech acts in small face-to-face meetings.

\begin{tabular}{|l|l|l|l|}
\hline & Direct & Indirect & Total \\
\hline Directives & $47(22 \%)$ & $166(78 \%)$ & $\mathbf{2 1 3 ( 1 0 0 \% )}$ \\
\hline Commissives & $12(29 \%)$ & $30(71 \%)$ & $\mathbf{4 2 ( 1 0 0 \% )}$ \\
\hline Expressives & $9(53 \%)$ & $8(47 \%)$ & $\mathbf{1 7}(\mathbf{1 0 0} \%)$ \\
\hline Declaratives & $0(0 \%)$ & $17(100 \%)$ & $\mathbf{1 7}(\mathbf{1 0 0} \%)$ \\
\hline Total & $\mathbf{6 8}$ & $\mathbf{2 2 1}$ & $\mathbf{2 8 9}$ \\
\hline ChiSq= & $\mathbf{1 4 . 2 5 0 8 6 4 1 6}$ & $\mathbf{d f = 3}$ & $\mathbf{p}<\mathbf{0 . 0 0 3}$ \\
\hline
\end{tabular}

Table 13 - Non-assertives in small group

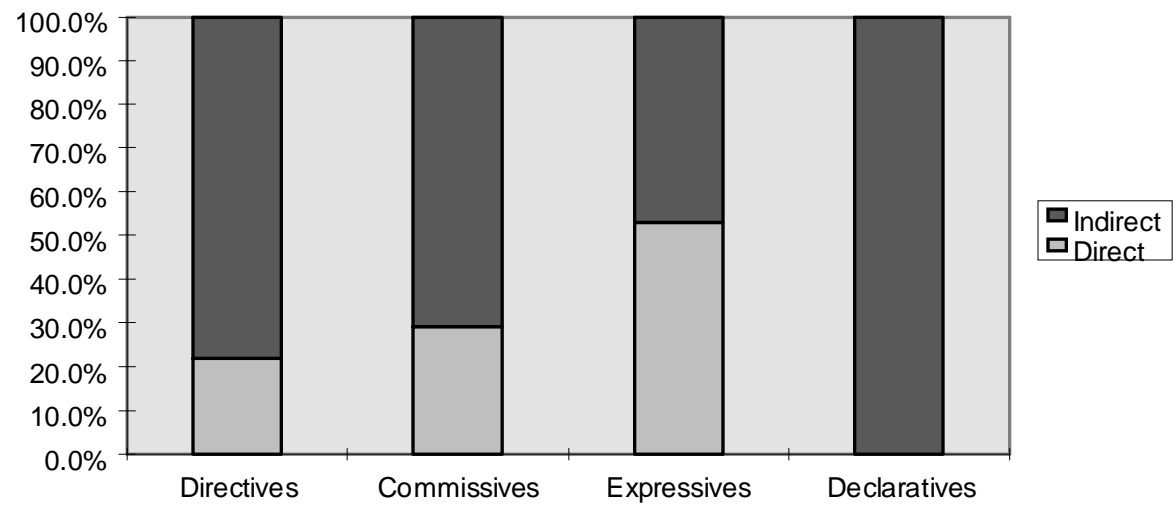

Figure 10 - Non-assertives in small group by percentage

\subsubsection{Telephone}

The sparseness of data for over half the cells in this contingency table makes the chi-square meaningless. The relatively high number of direct expressives cannot be given any weight $(\mathrm{p}>0.1)$. 


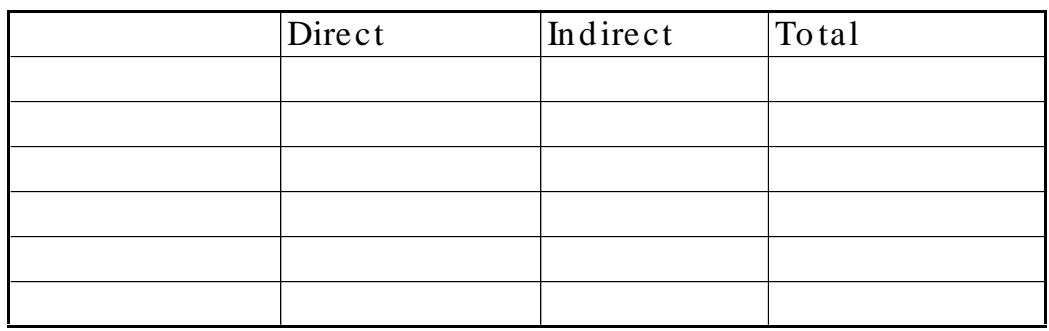

Table 14 - Non-assertives in telephone

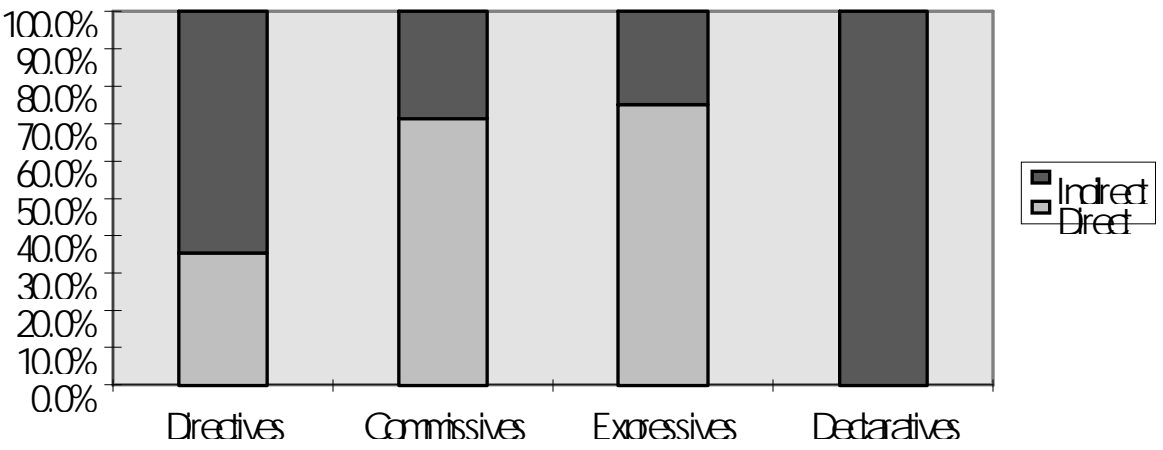

Figure 11 - Non-assertives in telephone by percentage

\subsubsection{Email}

Because there are almost no data for declaratives, we cannot make any statistically valid statement about the distribution of speech acts in email ( $p>0.1)$. Still, we can see that the indirect forms of speech acts outnumber the direct. We can also see that expressives represent $10 \%$ of speech acts in email, whereas in telephone and face-toface they represent only $2.4 \%$ and $1.5 \%$ respectively (Table $4, \mathrm{p}<0.001$ ). But there is a more interesting number. It will be noted that half of all expressives in email are direct, whereas only $25 \%$ of expressives are direct in faceto-face. Is the writer of an email message trying to "personalize" an impersonal medium? Perhaps, but if this is the case, it falls upon the reader to comprehend that the writer is not directing "excess" emotion to him/her but toward the medium. Email, unfortunately, is a relatively young medium and "rules" for this has yet to emerge.

\begin{tabular}{|l|l|l|l|}
\hline & Direct & Indirect & Total \\
\hline Directives & $36(39.1 \%)$ & $56(60.9 \%)$ & $92(100 \%)$ \\
\hline Commissives & $16(43.2 \%)$ & $21(56.8 \%)$ & $37(100 \%)$ \\
\hline Expressives & $20(50 \%)$ & $20(50 \%)$ & $40(100 \%)$ \\
\hline Declaratives & $0(0 \%)$ & $1(100 \%)$ & $1(100 \%)$ \\
\hline Total & 72 & 98 & 170 \\
\hline ChiSq= & 2.0960601 & df $=3$ & NSS \\
\hline
\end{tabular}

Table 15 - Non-assertives in email

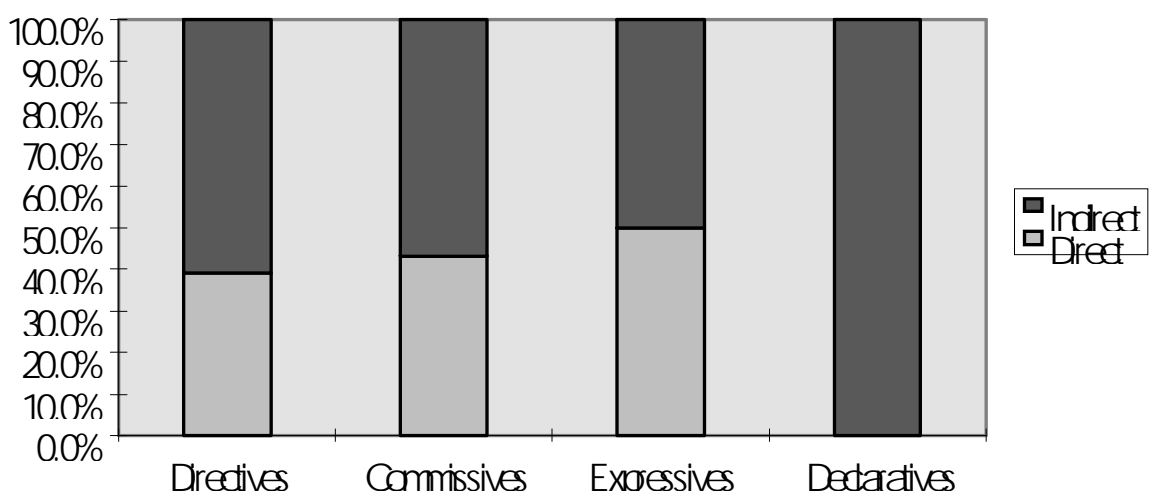

Figure 12 - Non-assertives in email by percentage 


\subsection{Summary of Findings}

In fine, this study has produced the following findings:

A. Depending on the channel, $17 \%-30 \%$ of all assertives were used to express other speech acts indirectly (Table 5).

B. Overall, directives, commissive, expressives and declaratives occurred more frequently in the indirect form than in the direct form (Tables $6,7,8,9$ ) and in different proportions .

C. There were proportionately more expressives in email than in face-to-face (Table 4).

D. Expressives in email were made in the direct form far more frequently than they are in face-to-face. Only $25 \%$ of expressives were direct in face-to-face, whereas $50 \%$ of all expressives were direct in email (Table $8)$.

\section{Conclusions}

From the results of this study, it would seem that most writers on the subject have ignored an important element in communication: the indirect form of communication. Those researchers who did take into account the broader linguistic element in CSCW stressed unambiguous communication, i.e., direct speech acts (Winograd and Flores [10], Woo and Chang [11], etc.). It may be that indirect speech acts were not important for one reason or another in their studies. To model all communicative activity only on direct speech acts, however, would seem not to provide a complete model. Searle does state that any indirect speech act must in principle be translatable into one of similar meaning in the direct form. On the other hand, by doing so, one would lose an important social element (i.e., an element of context). Winograd and Flores would certainly seem to be correct in their assertion that to use systems developed with the language/action method will result in users learning a new "ontology of language." However, to what degree they can be taught this and to what degree they will develop one for themselves is a matter of debate. One might argue that making requests, commitments and declarations explicit makes communication more efficient. This study, however, raises a number of questions in this regard. Given the heavy use of the indirect form that occurs in natural communication, one must ask if this directly translating the indirect into the indirect form is felicitous, to borrow a term from Austin? What would be the effects of the breakdown that would result in the process of instruction? And whether it would produce more effective communication depends on the degree to which cultural and social strictures concerning politeness and decorum can readily be unlearned.

While speech act theory may be an imperfect yard stick of human communication, it is nevertheless a useful tool. Whatever shortcomings Searle's approach to pragmatics may be, it still provides a reasonably objective tool by which to measure certain aspects of linguistic activity. Modifications of it may need to be made in the future. Until such time as it shows itself to be fatally flawed -- and these flaws must be demonstrated empirically -- it provides a useful tool.

This study has shown the importance played by indirect speech acts in all communication, including electronic communication. Systems that have been developed using speech act theory as a model have employed direct speech acts in their model. The finding of the importance played by indirect speech acts indicates that much more work has to be done in the analysis of human-computer interface design as well as modeling to take into account indirect speech acts.

\section{References}

1. Austin, J.L., 1962, How to Do Things with Words, Harvard University Press.

2. Bowers, J. and Churcher, J., (1988), "Local and Global Structuring of Computer Mediated Communication: Developing Linguistic Perspectives on CSCW in COSMOS," Office: Technology and People, 4 (3); originally in CSCW '88: Proceedings of the Conference on Computer Supported Cooperative Work, ACM, New York.

3. Feenberg, A., (1989), "A User's Guide to the Pragmatics of Computer Mediated Communication," Semiotica, Vol. 75, Nos. 3/4, pp. 257-278. 
ELECTRONIC WORKSHOPS IN COMPUTING

Series edited by Professor C.J. van Rijsbergen

Frank Dignum, Jan Dietz, Egon Verharen and Hans Weigand, (Eds)

\section{Communication Modeling - The Language/Action Perspective}

Proceedings of the First International Workshop on Communication

Modeling, Tilburg, The Netherlands, 1-2 July 1996

\section{Indirect Speech Acts and Their Use in Three Channels of Communication}

Lewis Hassell and Margaret Christensen 
4. Gazdar, G., (1981), "Speech Act Assignment," in Joshi, Weber \& Sag (eds.), Elements of Discourse Understanding, Cambridge University Press.

5. Hjelmquist, Erland, (1993), "Communication between People using a Computer-mediated Communication System," in Michael J. Smith and Gavriel Salvendy (Eds.) Human-Computer Interaction: Applications and Case Studies, Elsevier.

6. Levinson, S. C., (1983), Pragmatics, Cambridge University Press.

7. Searle, J., (1969), Speech Acts, Cambridge University Press.

8. Searle, J., (1979), Expression and Meaning, Cambridge University Press.

9. Searle, J. and Vanderveken, D., (1985), The Foundations of Illocutionary Logic, Cambridge University Press.

10. Winograd, T. and Flores, F., (1986), Understanding Computers and Cognition, Addison Wesley.

11. Woo, C. C. and Chang, M. K., (1992), "An Approach to Facilitate the Automation of Semistructured and Recurring Negotiations in Organizations," Journal of Organizational Computing, Vol. 2 No.1, pp. 47-76. 